\title{
Role of tangential force coefficient on fretting fatigue life estimation of a single crystal Ni-base superalloy
}

\author{
Balavenkatesh RENGARAJ*, Sotaro BABA* and Masakazu OKAZAKI** \\ * Graduate School of Mechanical Engineering, Nagaoka University of Technology \\ 1603-1 Kamitomioka-machi, Nagaoka-shi, Niigata 940-2188, Japan \\ E-mail: s127014@stn.nagaokaut.ac.jp \\ ** Department of Mechanical Engineering, Nagaoka University of Technology \\ 1603-1 Kamitomioka-machi, Nagaoka-shi, Niigata 940-2188, Japan
}

Received: 25 March 2017; Revised: 30 July 2017; Accepted: 10 September 2017

\begin{abstract}
Fretting fatigue behavior of Ni-base superalloys used in gas turbine blades and disk assemblies have been investigated under ambient and high temperature conditions. A major emphasis was placed on the influence of experimentally measured tangential force coefficient on the fretting fatigue life prediction of a single crystal superalloy. Significant differences in the experimental fretting fatigue lives with respect to contacting superalloy combinations were found. These experimental findings were correlated with an analytical approach for the estimation of fretting fatigue life. The predicted results employing the crack analogue model provided good agreement with the experimental results. Also, the influence of secondary crystal orientation of single crystal superalloy on the frictional response and fretting fatigue life prediction was highlighted.
\end{abstract}

Keywords : Fretting fatigue, Superalloys, Anisotropic, Fatigue life prediction, Crack analogue model

\section{Introduction}

Heat resistant materials such as Ni-base superalloys have been widely used in the hot section components of modern aircraft and power-generation gas turbine engines. Especially, gas turbine blades are casted as single crystals of Ni-base superalloys, while disks are manufactured from polycrystalline Ni-base superalloys (Reed, 2006). Fretting fatigue in gas turbine blade-disk attachment occurs due to small oscillating surface displacements (fretting) in addition to the bulk stresses (fatigue). When fretting occurs together with fatigue it accelerates the crack nucleation and it can lead to drastic reduction in fatigue life of the component (Waterhouse, 1981a). Several literatures are available on the fretting fatigue behavior of various steels, $\mathrm{Al}$ alloys and Ti alloys. However, studies on the fretting fatigue behavior of heat resistant superalloys, more specifically, on the single crystal Ni-base superalloys are limited (Mall et al., 2010, Murthy et al., 2006). Previous studies on fretting behavior of engineering alloys have identified that the coefficient of friction $(C O F)$ is one of the primary variables which affect the fretting process (Dobromirski, 1992). For the case of single crystal Ni-base superalloy components, the crystallographic orientation with respect to loading directions could affect the mechanical strength properties such as high cycle fatigue (HCF), thermo-mechanical fatigue (TMF) and creep behavior (Matan et al., 1999). Huang et al. (2009) reported a crystallographic effect on the room temperature (RT) fretting wear response in terms of $C O F$ for two different crystal orientations. Recently, Fleury et al. (2014) investigated the effect of the crystal orientation of a single crystal contact pad on the fretting fatigue life of polycrystalline Ni-base superalloy. Some analytical trials employing mechanistic approaches have also been made to estimate the fretting fatigue lives of engineering alloys (Giannakopoulos et al., 1998, 1999).

In this study, the roles of fretting induced tangential force evolution and secondary crystallographic orientation on fretting fatigue life were investigated at first, by using a combined single crystal and polycrystalline superalloy contacting pair. These tests were carried out by the same procedure as in our previous research (Rengaraj et al., 2016). Next, main focus was put on fretting fatigue life prediction, correlating the experimental results with the results of analytical study 
which employs a crack analogue model (Giannakopoulos et al., 1998). Furthermore, a possible effect of variation in tangential force coefficient (TFC) with secondary crystallographic orientation $(\beta)$ was also discussed.

\section{Experimental procedure}

\subsection{Materials and specimens}

Single crystal (SC) Ni-base superalloy, CMSX-2; a representative material for gas turbine blades, was used in this study after standard solution heat treatment and aged conditions. A polycrystalline (PC) Ni-base superalloy, IN718; a representative material for gas turbine disks, was used as a contacting body. The chemical compositions and mechanical properties of the contacting superalloys used in this study are presented in Table 1 and Table 2, respectively. SC specimens for fretting fatigue tests were machined from CMSX-2 bar stock as per dimensions shown in Fig. 1(a). The [001] crystallographic orientation was within $\pm 5^{\circ}$ of the longitudinal axis of the specimen. The dimensions of PC contact pad is shown in Fig. 1(b). Specimens from PC IN718 superalloy were also machined. Contact surfaces of specimen and contact pads were polished with SiC papers up to P-600 along the fretting direction.

Table 1 Chemical compositions (wt\%) of Ni-base superalloys used in this study.

\begin{tabular}{lcccccccccccc}
\hline Material & $\mathrm{Cr}$ & $\mathrm{Co}$ & $\mathrm{Mo}$ & $\mathrm{W}$ & $\mathrm{Ti}$ & $\mathrm{Al}$ & $\mathrm{Ta}$ & $\mathrm{Hf}$ & $\mathrm{Fe}$ & $\mathrm{C}$ & $\mathrm{Nb}$ & $\mathrm{Ni}$ \\
\hline SC CMSX-2 & 7.9 & 4.6 & 0.6 & 7.9 & 1.0 & 5.6 & 6.0 & 0.1 & - & - & - & Bal. \\
\hline PC IN718 & 19.0 & - & 3.0 & - & 0.9 & 0.5 & - & - & 18.0 & 0.04 & 5.0 & Bal. \\
\hline
\end{tabular}

Table 2 Mechanical properties of SC alloy and PC alloy (Zhang et al., 2001, Shah and Duhl, 1984).

\begin{tabular}{lcccc}
\hline Property & \multirow{2}{*}{ Unit } & \multicolumn{2}{c}{ SC alloy } & \multirow{2}{*}{ PC alloy } \\
\cline { 3 - 4 } & & $\beta=0^{\circ}$ & $\beta=45^{\circ}$ & \\
\hline Longitudinal modulus & $E[\mathrm{GPa}]$ & 124 & 226 & 204 \\
\hline Shear modulus & $G[\mathrm{GPa}]$ & 127 & 66 & 78 \\
\hline Yield strength & $\sigma_{Y}[\mathrm{MPa}]$ & 1150 & 1020 & 925 \\
\hline Microhardness & $H v$ & $562 \pm 27$ & $471 \pm 18$ & $479 \pm 31$ \\
\hline
\end{tabular}

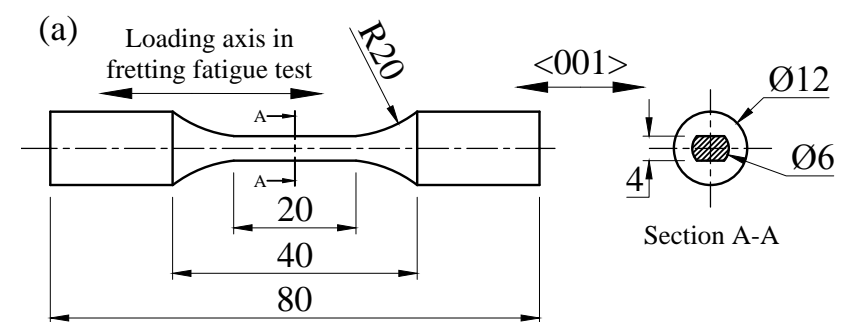

(b)

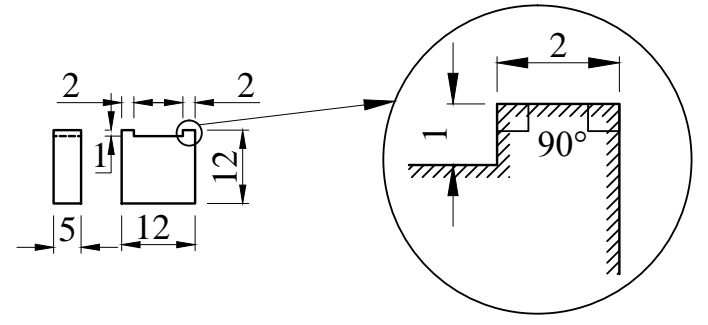

Fig. 1 Geometries of (a) CMSX-2 fretting fatigue test specimen (b) IN718 contact pad. All dimensions are in $\mathrm{mm}$.

\subsection{Fretting fatigue tests}

The fretting fatigue tests were conducted by applying cyclic bulk loading (Stress ratio, $R=-1$ and Frequency, $f=10$ $\mathrm{Hz}$ ) to the longitudinal axis and contact pressure to the transverse axis using a flat-on-flat fretting contact arrangement on a servo-hydraulic test machine as shown in Fig. 2. With respect to contacting superalloys, two sets of contact combinations were tested as follows: (i) SC specimen fretted against PC contact pads (SC/PC) and (ii) PC specimen fretted against PC contact pads (PC/PC). Hence, it is possible to evaluate the fretting strength of SC blade material with reference to PC disk material. For the tests at $600^{\circ} \mathrm{C}$, the specimen and contact pads were heated using a high frequency induction heating 
equipment. A constant contact pressure $\left(\sigma_{p}=100 \mathrm{MPa}\right)$ was applied by pressing a pair of PC contact pads on either side of the specimen surface using a calibrated proving ring. Fretting fatigue test was carried out until failure to determine the fretting fatigue life for a given stress amplitude. The secondary crystallographic orientation $(\beta)$ with respect to fretting contact plane normal of SC specimen is schematically shown in Fig. 3. $\beta$ angles of the SC specimens were not controlled but measured values are presented in Table 3.

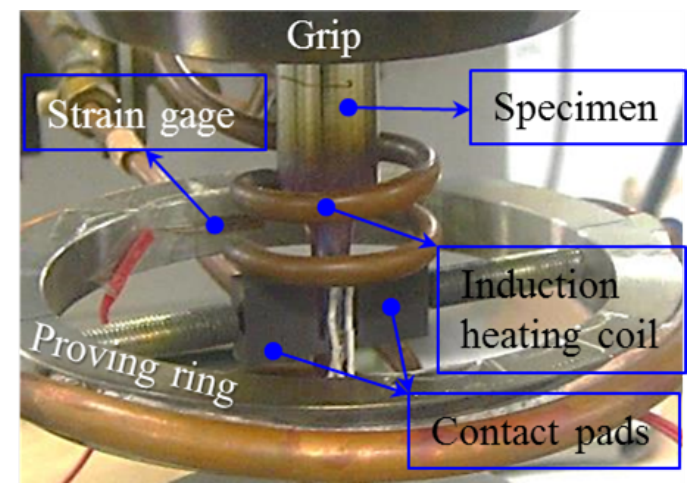

Fig. 2 Photograph of high temperature fretting fatigue test rig system utilized in this study. A constant contact pressure was applied by means of proving ring.

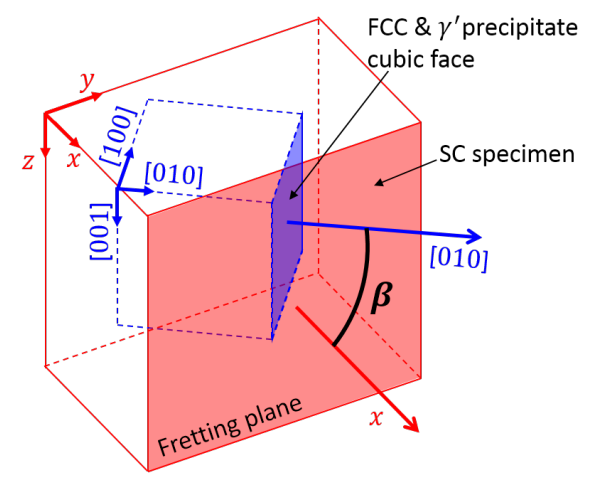

Fig. 3 Schematic representation of secondary crystallographic orientation $(\beta)$ angle between fretting plane normal and FCC SC cubic principal direction.

Table 3 Secondary crystallographic orientations $(\beta)$ of SC specimens used in fretting fatigue tests.

\begin{tabular}{ccc}
\hline \multirow{2}{*}{ Test temperature } & $\begin{array}{c}\text { Stress amplitude, } \sigma_{a p p} \\
{[\mathrm{MPa}]}\end{array}$ & $\begin{array}{c}\beta \text { (from }<010>\text {, see } \\
\text { Fig. 3 ) }\end{array}$ \\
\hline \multirow{3}{*}{$\mathrm{RT}$} & 100 & $\sim 25^{\circ}$ \\
\cline { 2 - 3 } & 150 & $\sim 40^{\circ}$ \\
\cline { 2 - 3 } & 250 & $\sim 5^{\circ}$ \\
\cline { 2 - 3 } & 400 & $\sim 20^{\circ}$ \\
\hline \multirow{2}{*}{$600^{\circ} \mathrm{C}$} & 200 & $\sim 15^{\circ}$ \\
& 300 & $\sim 45^{\circ}$ \\
\hline
\end{tabular}

\subsection{Measurement of tangential force}

The tangential force between the specimen and contact pad was continuously measured using a pair strain gages attached to the groove part of the contact pads. For this purpose, prior to testing, fretting pads were calibrated using a split specimen technique. Then, the tangential force coefficient (TFC) was calculated using Eq. (1).

$$
T F C=\frac{Q}{P}
$$

where $Q$ is the measured tangential force amplitude per unit length and $P$ is the normal force per unit length applied on the specimen surface via proving ring. 


\section{Experimental results and discussions}

\subsection{Experimental fretting fatigue life: $\mathrm{S}-\mathrm{N}$ curve}

The outline of experimental results of SC superalloy has been already given in the reference (Rengaraj et al., 2016), however, for better undetstanding of later Section 4, the core part is briefly surveyed again by comparing the experimental results of PC superalloy as below. Fig. 4 shows the relationship between applied bulk stress amplitude $\left(\sigma_{\text {app }}\right)$ and number of cycles to failure $\left(N_{f}\right)$ of SC and PC superalloys fretted against PC superalloy. Reference room temperature plain fatigue tests were also conducted and high temperature plain fatigue results of SC alloy are taken from literatures (Okazaki et al., 1992, Harris, 1982). In comparison to plain fatigue life, the fretting fatigue life of the superalloys was reduced by a factor of 0.2 0.3, which clearly shows the detrimental effect of fretting on the fatigue life of the component. With respect to contact pair, fretting fatigue strength of SC/PC contact pair was found to be lower than that of PC/PC contact pair. Fretting fatigue strength (at $N=1 \times 10^{7}$ ) was $150 \mathrm{MPa}$ for PC/PC and was $100 \mathrm{MPa}$ for SC/PC. Little is known on the effect of secondary crystallographic orientation from the S-N curve, as the SC specimens tested at different stress amplitudes had different secondary orientations (Table 3). Possible influence of secondary crystallographic orientation of SC specimen on the fretting fatigue life will be discussed in Section 4.3 .

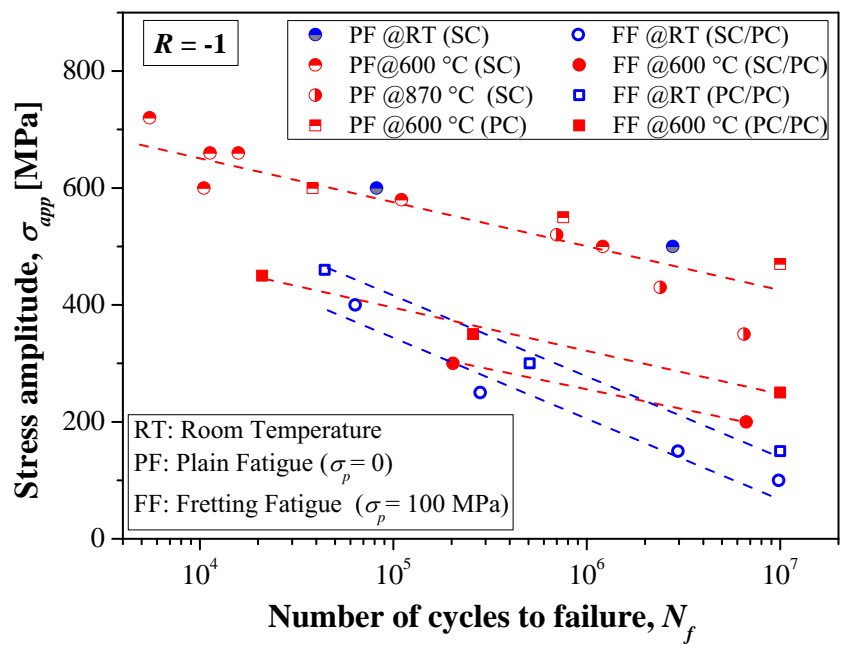

Fig. 4 S-N data for plain fatigue and fretting fatigue of Ni-base superalloy combinations $\left(\sigma_{p}=100 \mathrm{MPa}\right)$. Detrimental effect of fretting on the fatigue life of superalloys is evident. Fretting fatigue strength of SC CMSX-2 was lower than PC IN718(Rengaraj et al., 2016).

Test temperature did not affect the plain fatigue life of the superalloys. On the other hand, fretting fatigue life was improved slightly at high temperature when the applied bulk stress amplitude was low enough. Mall et al. (2010) reported a significant improvement in plain fatigue and fretting fatigue performance of IN100 alloy at $600^{\circ} \mathrm{C}$. Such temperature dependent fatigue behavior was linked to the increase in yield and tensile strengths of Ni-base superalloys at intermediate temperatures (Mall et al., 2010). Waterhouse (1981b) reported the formation of oxide layer on the surface of IN718 alloy subjected to fretting at $540^{\circ} \mathrm{C}$ that resulted in low $C O F$ and wear rate. Similar response was observed in the current study, where the formation of oxide layer at high temperature could have reduced the tangential force at the interface which must have delayed the crack nucleation process. However, such a temperature dependent behavior was observed only under lower stress amplitudes. Fleury et al. (2014) noted possible effect of exposure time in forming the oxide layer on the contact interface, where longer exposure time would increase the thickness of oxide layer. Hence, longer exposure time (number of cycles) under lower stress amplitudes resulted in the reduction of TFC. Thus, the knowledge of contact tractions at the interface with respect to contacting materials and operating environment is inevitable.

\subsection{Contact tractions during fretting fatigue test: $T F C$}

Fig. 5 shows the variation of mean $T F C$ with applied bulk stress amplitude for a constant contact pressure of 100 $\mathrm{MPa}$ at room temperature (RT). The increase in TFC was found to be linearly proportional to stress amplitude (at least in the range of tested stress amplitudes). Similar proportional relationship was also found in fretting fatigue of steel/steel contact pair (Okane et al., 2000). With respect to contacting superalloy combinations, mean TFC during fretting fatigue test of SC/PC fretting pair was higher than that of PC/PC pair. This is in agreement with the cyclic sliding friction behavior of contacting superalloys, where the COF for SC/PC sliding pair was higher than PC/PC pair (Rengaraj et al., 
2016). From Table 2, it can be seen that the yield strength of the PC alloy is lower than that of SC alloy. This result in considerable differences in surface microhardness of the superalloys. The resulting stress state under fretting contact should be a function of the mechanical properties of the materials in contact. Hence, as a primary postulation, when the PC contact pad is pressed against SC specimen having relatively higher yield strength and hardness, as can be seen from Table 2, resulted in considerably higher surface tractions which could have increased the TFC.

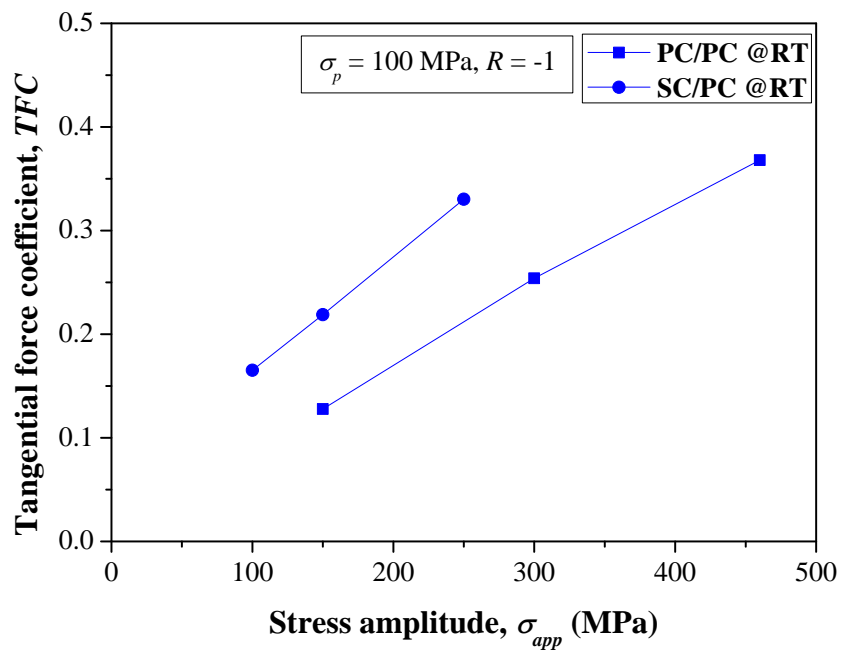

Fig. 5 Relationship between applied stress amplitude $\sigma_{a p p}$ and measured mean tangential force coefficient $T F C$ at RT $\left(\sigma_{p}=100 \mathrm{MPa}\right)$. Proportional relationship between $T F C$ and $\sigma_{a p p}$ together with a higher TFC for $\mathrm{SC} / \mathrm{PC}$ pair reflected in the reduction of fretting fatigue life of SC/PC pair.

Hence, the increase in $T F C$ for SC/PC pair could be the reason for the reduction in fretting fatigue life (Fig. 4). Thus, it is clear that the influence of stress amplitude on TFC (i.e. TFC as a function of stress amplitude) which could control fretting fatigue crack initiation needs to be taken into account for a better life prediction methodology. In the next section, an attempt was made to estimate the fretting fatigue life of superalloys by incorporating experimentally measured $T F C$ values into an analytical model based on crack analogue, which was proposed by Giannakopoulos et al. (1998).

\subsection{Fretting fatigue fracture behavior}
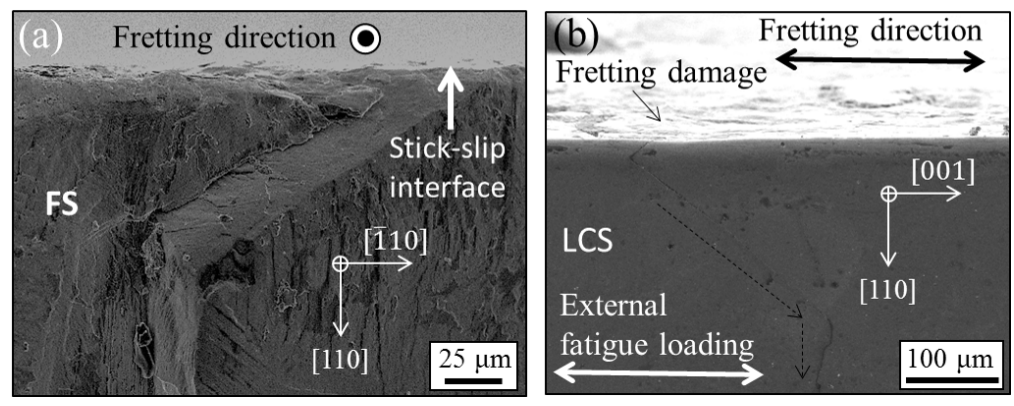

Fig. 6 Fracture morphology of SC CMSX-2 tested at RT (a) plan view of fracture surface (FS) showing inclined crack nucleation from stick-slip interface (location of localized stress concentration) and (b) longitudinal cross section (LCS) of the same specimen suggesting two stage crack propagation as a result of competition between contact stresses and applied bulk stress amplitude $\left(\sigma_{a p p}=300 \mathrm{MPa}\right)$.

Typical near surface fracture morphology observed in SC CMSX-2 specimen subjected to fretting fatigue is shown in Fig. 6(a). Fig. 6(b) shows the longitudinal cross section (cut along the fatigue loading axis) of the specimen shown in Fig. 6(a). The primary crack was nucleated from the stick-slip interface (location of high stress concentration) at an inclined angle to the fretting surface (stage A) (Fig. 6(a)). Then, the crack was reoriented to grow in a direction normal to the external fatigue loading axis (stage B). This transition can be attributed to the competition between contact stresses arising from fretting action and the bulk stress amplitude. In our previous study, in addition to primary crack propagation into the material, secondary cracks and surface cracks were also found to be grown as a result of localized stress concentrations along stick-slip interface (Rengaraj et al., 2016). These experimental evidences suggest that the 

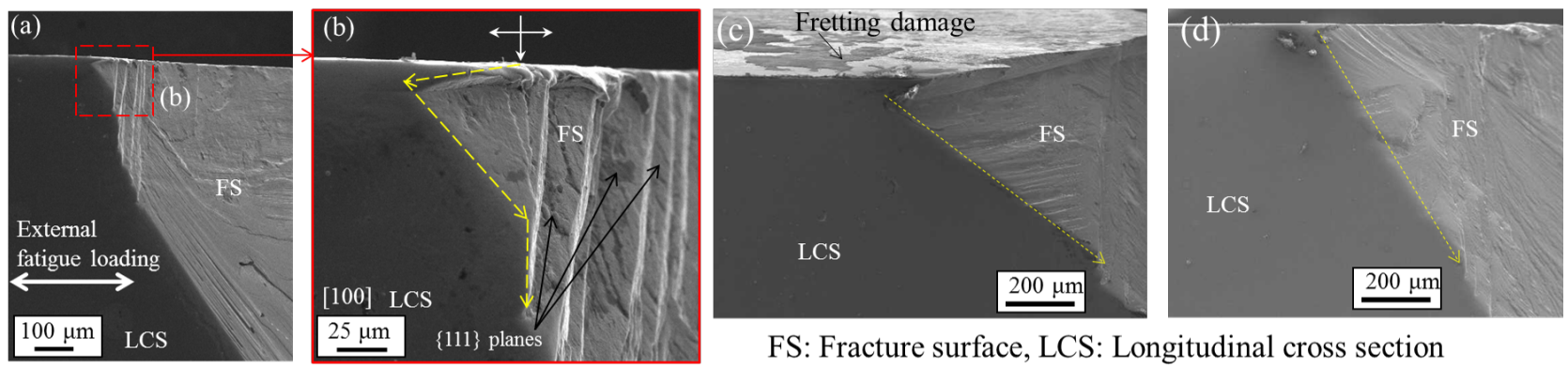

FS: Fracture surface, LCS: Longitudinal cross section

Fig. 7 Longitudinal cross section (LCS) micrographs of SC CMSX-2 tested at RT subjected to different stress amplitudes (a) $\sigma_{a p p}=250 \mathrm{MPa}$, (b) magnified image of inset shown in (a); suggesting the activation of multiple slip systems and crack propagation along multiple planes resulting in $\{111\}$ facets, (c) $\sigma_{a p p}=300 \mathrm{MPa}$, and (d) $\sigma_{a p p}=400 \mathrm{MPa}$. Co-existence of crystallographic (microscopic scale) and noncrystallographic (macroscopic scale) crack propagation modes resulted in random crack initiation and propagation planes.

fretting fatigue crack initiation occurred within few thousand fretting cycles as also reported by other researchers (Endo et al., 1976, Waterhouse, 1981a, Hattori et al., 2003, Mutoh et al., 2003).

The longitudinal cross section micro-graphs of SC CMSX-2 Specimens tested at different stress amplitudes are shown in Fig. 7. Significant differences in crack initiation and propagation angles with respect to loading conditions can be seen. Crack propagation along a set of $\{111\}$ planes suggest the activation of multiple slip systems, thus resulting in random macroscopic crack propagation paths, as can be seen in Fig. 7(b). In other words, crack propagation occurred along multiple microscopic slip planes connected by macroscopic step-like propagation directions. Based on these fractographic analyses and other researches (Endo et al., 1976, Waterhouse, 1981a, Hattori et al., 2003, Mutoh et al., 2003), a fretting fatigue life estimation model must be utilized focusing on the crack propagation process, which will be discussed in the following section.

\section{Fretting fatigue life estimation}

\subsection{Crack analogue (CA) model}

Giannakopoulos et al. (1998) used the analogy in stress state between contact mechanics and fracture mechanics, thereby introducing a methodology to estimate fretting fatigue life, by considering the two stages of crack growth, as shown in Fig. 8. They also highlighted the influence of $C O F$ on the crack initiation angle and effective stress intensity factors acting on the crack tip. Crack analogue (CA) model is employed in this work to estimate the fretting fatigue life by incorporating experimentally measured $T F C$ values (Fig. 5). In principle, the CA model is based on an analogy in stress field between crack and contact problems, while the order of stress singularity is different between them. Here the stress singularity order, $n\left(\sigma_{i j}(r)=H / r^{n}\right.$, where $r$ is the distance from singularity point, and $H$ is the intensity of stress singularity), around the contact point depends on the counterpart material and the contact angle (Hattori et al., 2003). The value of $n$ varies between 1 and 0 ; meanwhile its value for a crack is " $n=0.5$ " (Hattori et al., 2003). In other words, it is too difficult to explicitly evaluate the $n$ value which changes during the fretting fatigue crack propagation process. Rather, one of better ways from engineering viewpoint is to employ an assumption that the $n$ value can be approximated by 0.5 and then to get a knowledge on the limitation of the analogy. This is the background why the CA model was tried to be applied to the present study. For the sake of completeness, this section derives the important parameters considered in the CA model (Giannakopoulos et al., 1998).

(a) Stress intensity factors The remote stress intensity factors, $K_{I}$ and $K_{I I}$ due to normal line force $P$ and tangential line force $Q$ are given by,

$$
K_{I}=-\frac{P}{\sqrt{\pi a}}, \quad K_{I I}=\frac{Q}{\sqrt{\pi a}} .
$$

where, $a$ is the half-width of the contact pad foot.

The local stress intensity factors at the tip of incipient small crack initiating from the surface, $k_{1}$ and $k_{2}$ can be computed in terms of remote $K_{I}$ and $K_{I I}$ by (Cotterell and Rice, 1980):

$$
\begin{aligned}
& k_{1}=a_{11}(\phi) K_{I}+a_{12}(\phi) K_{I I} \\
& k_{2}=a_{21}(\phi) K_{I}+a_{22}(\phi) K_{I I}
\end{aligned}
$$



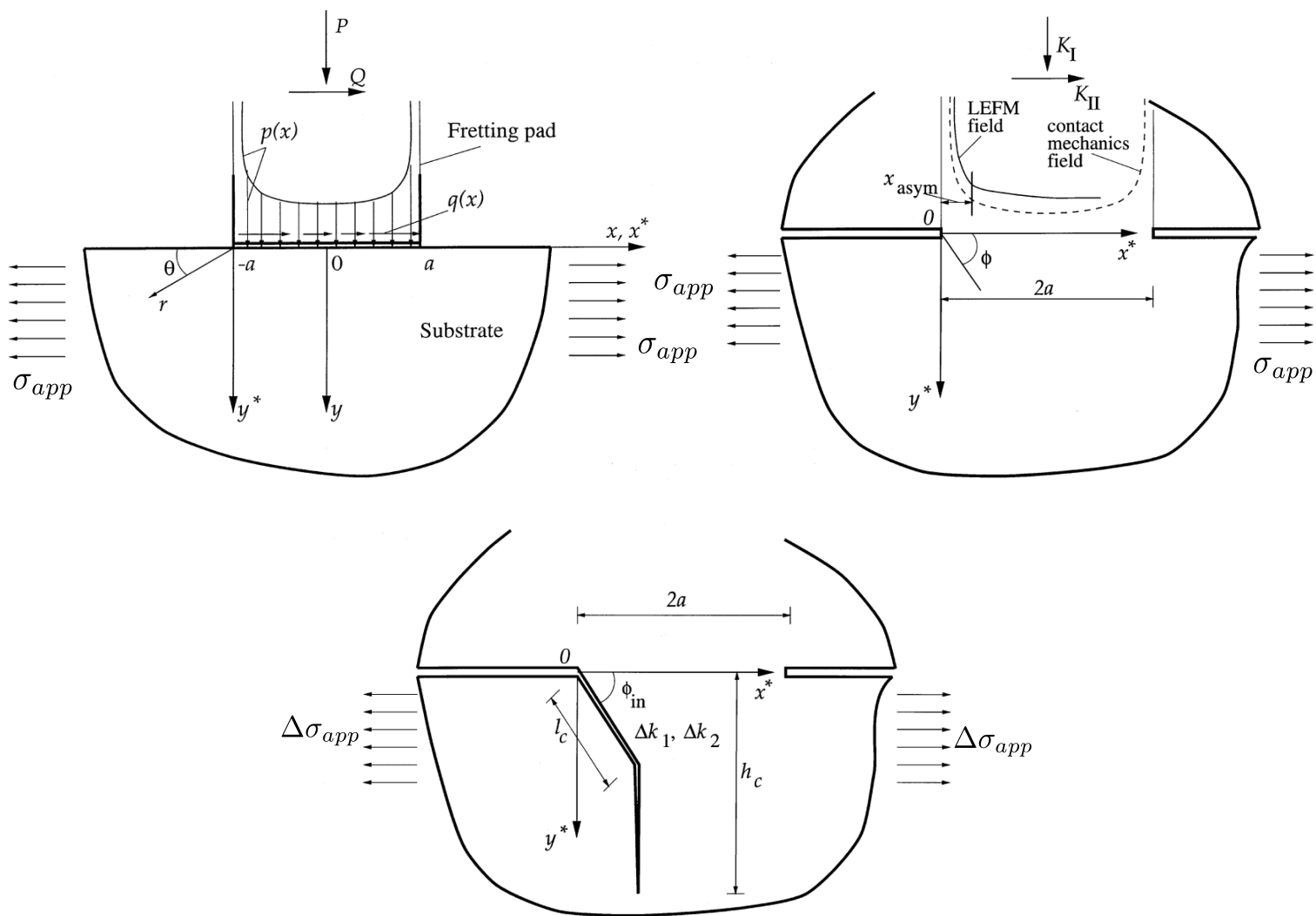

Fig. 8 Crack analogue model (a) fretting contact of flat punch (contact pad) and infinite half-plane (specimen) subjected to normal and tangential forces, (b) crack analogue of (a) as a double-edge cracked specimen subjected to mode I and mode II SIFs, and (c) schematic of two stage crack propagation analysis using crack analogue model (Giannakopoulos et al., 1998).

where, $a_{i j}$ - dimensionless factors (function of crack initiation angle) for the infinitesimal kink (after Cotterell and Rice (1980)).

(b) Crack initiation angle, $\phi_{i n} \quad$ It is assumed that the crack is initiating in a direction along which $k_{2}$ is zero, i.e. maximum shear energy direction. Thus the crack initiation angle $\phi_{i n}$ can be computed by solving the equations in Eq. (3) by invoking the condition that $k_{2}=0$ and is given by,

$$
\left(\sin \frac{\phi_{i n}}{2}+\sin \frac{3 \phi_{i n}}{2}\right) \times\left\{\left|\cos \frac{\phi_{i n}}{2}+3 \cos \frac{3 \phi_{i n}}{2}\right|\right\}^{-1}=\frac{Q_{\max }}{P}=T F C
$$

where, $T F C$ - tangential force coefficient

(c) Stage A crack growth life, $N_{\mathbf{1}} \quad$ A fatigue crack initiating at $\phi_{i n}$ is subjected to an effective stress intensity factor (arising from static $P$ and cyclic $Q$ ), $\Delta k_{1}$, given by,

$$
\Delta k_{1}= \pm \frac{3}{4} \Delta K_{I I}\left(\sin \frac{\phi_{\text {in }}}{2}+\sin \frac{3 \phi_{\text {in }}}{2}\right)
$$

The fatigue crack initiated at angle of $\phi_{i n}$ would first propagate under the influence of $P$ and $\Delta Q$ over a distance of $l_{c}$, before deflecting to propagate in a direction perpendicular to $\Delta \sigma_{a p p}$. This transition in crack growth occurs when the local driving force for fatigue crack growth due solely to $\Delta \sigma_{a p p}$ begins to exceed that due solely to $P$ and $\Delta Q$. At the critical length $l_{c}$, the local $\Delta k_{1}$ due to $\Delta \sigma_{a p p}$ is (Suresh, 1998):

$$
\left(\Delta k_{1}\right)_{\Delta \sigma_{a p p}}=1.12 \Delta \sigma_{a p p} \sqrt{\pi\left(l_{c} \sin \phi_{i n}\right)} \quad \geq\left(\Delta k_{1}\right)_{P, \Delta Q}
$$

Now number of cycles for stage A crack length can be computed using Paris law as follows,

$$
N_{1}=\int_{0}^{l_{c}} \frac{d l}{C\left(\Delta k_{1}\right)^{m}} \approx \frac{l_{c}}{C\left(\Delta k_{1}\right)^{m}}
$$


where, $C$ and $m$ are Paris law constants.

(d) Stage B crack growth life, $\boldsymbol{N}_{2} \quad$ Stage B of crack propagation is solely under the influence of $\Delta \sigma_{\text {app }}$ until a critical length, $h_{c}$, at which maximum SIF reaches the fracture toughness of the material, $K_{c}$ (for a very deep substrate):

$$
K_{\max }=1.12\left[\sigma_{\text {app }}\right]_{\max } \sqrt{\pi h_{c}} \rightarrow K_{c}
$$

where, $K_{c}$ - fracture toughness of the material.

Now, stage B life can be calculated as follows,

$$
N_{2}=\int_{l_{c} \sin \phi_{i n}}^{h_{c}} \frac{d l}{C\left(1.12 \Delta \sigma_{a p p} \sqrt{\pi l}\right)^{m}}
$$

\subsection{Comparison: Application of CA model to present work}

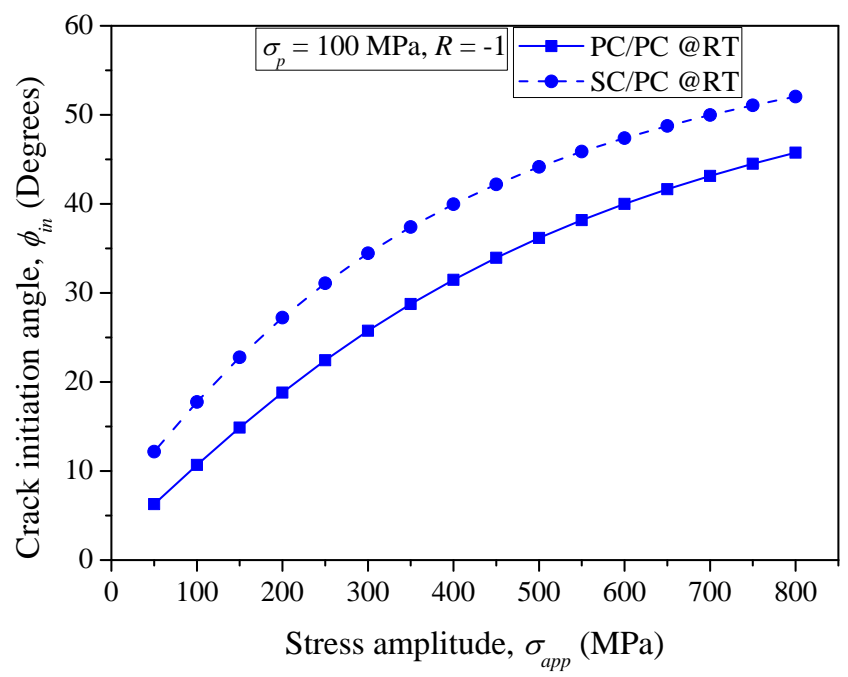

Fig. 9 Crack initiation angle $\left(\phi_{i n}\right)$ as a function of applied bulk stress amplitude $\left(\sigma_{a p p}\right)$. The increase in $\phi_{i n}$ with $\sigma_{a p p}$ can be approximated by a quadratic function. Material combination has also an effect on $\phi_{i n}$.

Table 4 Curve fit parameters calculated from RT fretting fatigue experiments.

\begin{tabular}{cccccc}
\hline Pair & $m_{1}$ & $c_{1}$ & $a_{2}$ & $b_{2}$ & $c_{2}$ \\
\hline PC/PC & $8 \times 10^{-3}$ & 0.0152 & $-5 \times 10^{-5}$ & 0.0926 & 2.0432 \\
\hline SC/PC & $1.1 \times 10^{-3}$ & 0.0542 & $-7 \times 10^{-5}$ & 0.1077 & 7.8196 \\
\hline
\end{tabular}

Table 5 Fatigue properties of PC superalloy (Ma et. al., 2010).

\begin{tabular}{cc}
\hline Property & Value \\
\hline$C\left[(\mathrm{MPa})^{-3} \mathrm{~m}^{-1 / 2}\right]$ & $3 \times 10^{-13}$ \\
\hline$m[-]$ & 4 \\
\hline$K_{c}\left[\mathrm{MPa} \mathrm{m}^{1 / 2}\right]$ & 130.8 \\
\hline
\end{tabular}

The CA model described in the previous section assumes that the TFC is constant for all the applied bulk stress amplitudes. However, in this work, the TFC was observed to vary linearly with stress amplitude. The variation of TFC with applied bulk stress amplitude during fretting fatigue tests is plotted in Fig. 5. Hence, it becomes necessary to incorporate the varying TFC in the CA model. From the Fig. 5, it is clear that the TFC can be fitted as a linear function of bulk stress amplitude as follows:

$$
T F C=m_{1} \sigma_{a p p}+c_{1}
$$

where $m_{1}$ and $c_{1}$ are experimental constants that depend on contact pair and loading conditions. 
Now the TFC can be used to solve for $\phi_{\text {in }}$ in Eq. (4). The calculated values of $\phi_{\text {in }}$ for two different contacting pairs are presented in Fig. 9, where $\phi_{\text {in }}$ (angle from the surface) gradually increased with the increase in bulk stress amplitude $\sigma_{a p p}$. The $\phi_{\text {in }}$ was fitted as a quadratic function of $\sigma_{a p p}$ as follows:

$$
\phi_{\text {in }}=a_{2} \sigma_{a p p}^{2}+b_{2} \sigma_{a p p}+c_{2}
$$

where $a_{2}, b_{2}$ and $c_{2}$ are curve fitting constants. The calculated values of empirical constants from the current fretting fatigue experiments on two contact pairs are presented in Table 4.
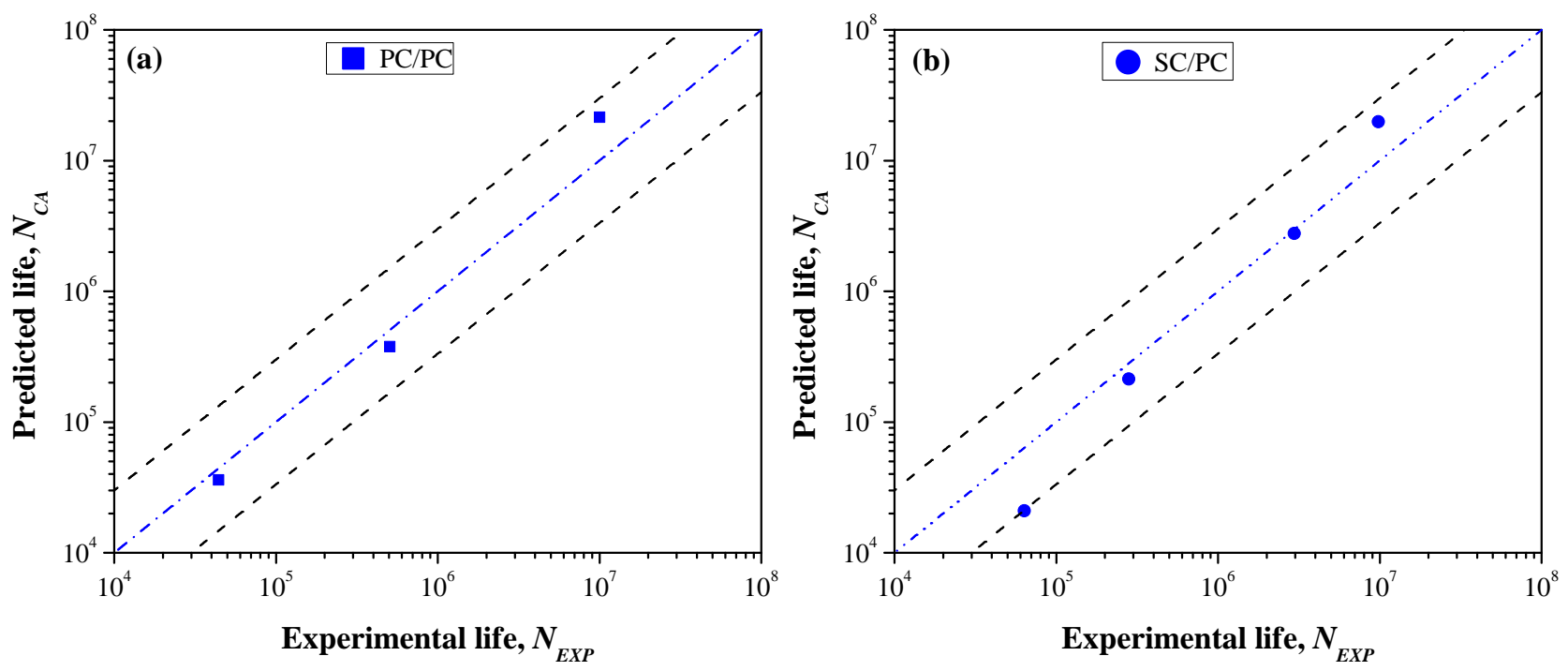

Fig. 10 Room temperature experimental life versus predicted life using CA model for (a) PC IN718 and (b)SC CMSX-2. The upper and lower scatter band curves represent $1 / 3$ and 3 times of $N_{C A}$. The estimated lives are in good agreement with experimentally measured lives.

The total number of cycles to failure $\left(N_{C A}=N_{1}+N_{2}\right)$ can now be calculated by incorporating Eqs. (10) and (11) together with the fatigue properties listed in Table 5, to calculate local SIFs through Eq. (2) to Eq. (8). Estimated cycles to failure curves for two different contacting superalloys pairs are plotted in Fig. 10 and are compared with experimental lives. The upper and lower scatter band curves (dashed) on either side of the predicted life curve (dotted-dashed) in Fig. 10, represent $1 / 3$ and 3 times the predicted fretting fatigue lives, respectively. A good correlation was found between predicted and experimental fretting fatigue lives. Note that the length of stage A and stage B cracks calculated in CA model are for deep substrate (under the assumption of infinite half-plane) although the actual specimens have finite width. However, CA model could still be effective for estimation of fretting fatigue life in terms of total number of cycles to failure.

\subsection{Extension of CA model to estimate the effect of secondary crystallographic orientation of SC}

For the case of contact between SC and PC alloys, the stress state below the contact must be sensitive to secondary crystallographic orientation of SC with respect to contact pressure direction (or fretting plane normal) (Rengaraj et al., 2016). In order to explore this aspect, fretting fatigue tests (under identical loading conditions) were carried out with SC specimens having different secondary crystallographic orientations $\beta$ as schematically shown in Fig. 3.

Fig. 11 shows the evolution of TFC with fretting fatigue cycles for two different $\beta$ orientations. Note that the applied contact pressure $\sigma_{p}$ was $100 \mathrm{MPa}$, for both orientations. However, the $T F C$ was observed to be higher for $\beta=45^{\circ}$ specimen than that of $\beta=5^{\circ}$ specimen. As one would expect, the specimen with higher $T F C\left(\beta=45^{\circ}\right)$ failed faster than the other specimen. Similar trends in cyclic sliding friction behavior and contact stress field with respect to secondary crystal orientation were confirmed in a previous study by the authors (Rengaraj et al., 2016). Thus, it is possible to estimate the fretting fatigue life of SC/PC fretting contact using CA model by incorporating the experimental knowledge of tangential force coefficient $T F C$ evolution with respect to secondary crystallographic orientation. 


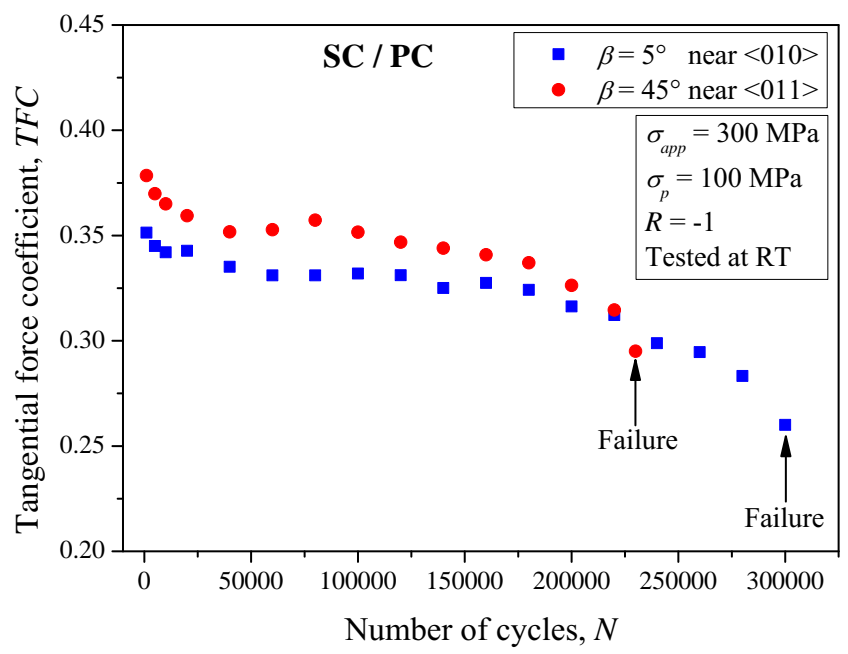

Fig. 11 Evolution of TFC with fretting fatigue cycles on SC specimens having two different secondary orientations under identical loading conditions. For the given loading conditions, the specimen with higher $T F C$ failed faster than the one with lower $T F C$.

\section{Conclusions}

Prediction of the fretting fatigue life of single crystal Ni-base superalloy components which was significantly affected by many factors was tried, employing the crack analogue model (CA model). The CA model provided reasonable estimations based on the TFC parameter, with respect to some representative influencing factors in fretting fatigue failure of superalloy components: those covered are the effects of stress amplitude and fretting contact pair. The predicted results agreed well with the experimental works. The CA model could also be applied to estimate the effect of secondary crystallographic orientation.

\section{Acknowledgments}

Financial support through the Ministry of Education, Culture, Sports and Technology (MEXT) scholarship, is greatly acknowledged by one of the authors Balavenkatesh Rengaraj. Okazaki Masakazu would like to thank the Japan Society for the Promotion of Science (JSPS) for financial support through grant-in-aid \#16H02304.

\section{References}

Cotterell, B. and Rice, J., Slightly curved or kinked cracks, International Journal of Fracture, Vol.16, No.2 (1980), pp.155169.

Dobromirski, J., Variables of fretting process: Are there 50 of them? In Attia, M. and Waterhouse, R. B., editors, Standardization of Fretting Fatigue Test Methods and Equipment, ASTM STP 1159 (1992), pp. 60-66.

Endo, K., and Goto, H., Initiation and propagation of fretting fatigue cracks, Wear, Vol.38, No.2 (1976), pp. 311-324.

Fleury, R. M. N., Paynter, R. J. H., and Nowell, D., The influence of contacting Ni-based single-crystal superalloys on fretting fatigue of Ni-based polycrystalline superalloys at high temperature, Tribology International, Vol.76 (2014), pp.63-72.

Giannakopoulos, A., Lindley, T., and Suresh, S., Aspects of equivalence between contact mechanics and fracture mechanics: theoretical connections and a life-prediction methodology for fretting-fatigue, Acta Materialia, Vol.46, No.9 (1998), pp.2955-2968.

Harris, K., High temperature alloys committee: Session on recent advanvces in Superalloy Technology, Technical report (1982).

Hattori, T., Nakamura, M., and Watanabe, T., Simulation of fretting-fatigue life by using stress- singularity parameters and fracture mechanics, Tribology International, Vol.36, No.2 (2003), pp.87-97.

Huang, X., Gibson, T. E., Zhang, M., and Neu, R. W., Fretting on the cubic face of a single-crystal Ni-base superalloy at room temperature, Tribology International, Vol.42, No.6 (2009), pp.875-885. 
Ma, X., Duan, Z., Shi, H., Murai, R., Fatigue and fracture behavior of nickel-based superalloy Inconel 718 up to the very high cycle regime, Journal of Zhejiang University-SCIENCE A (Applied Physics and Engineering), Vol.11, No.10 (2010), pp.727-737.

Mall, S., Kim, H., Porter, W. J., Ownby, J. F., and Traylor, A. G., High temperature fretting fatigue behavior of IN100, International Journal of Fatigue, Vol.32, No.8 (2010), pp.1289-1298.

Matan, N., Cox, D., Carter, P., Rist, M., Rae, C., and Reed, R., Creep of CMSX-4 superalloy single crystals: effects of misorientation and temperature, Acta Materialia, Vol.47, No.5, (1999), pp.1549-1563.

Murthy, H., Gao, G., and Farris, T. N., Fretting fatigue of single crystal nickel at $600^{\circ}$ C, Tribology International, Vol.39, No.10 (2006), pp.1227-1240.

Mutoh, Y., Xu, J.Q., and Kondoh, K., Observations and analysis of fretting fatigue crack initiation and propagation, Fretting Fatigue, STP 1425, ASTM International, West Conshohocken, PA, 2003, pp.61-75.

Okane, M., Shiozawa, K., and Ishikura, T., Fretting fatigue behavior of TiN-coated steel, In: Fretting Fatigue: Current Technology and Practices, ASTM STP 1367 (2000), pp.465-476.

Okazaki, M., Imai, T., Satoh, T., and Nohmi, S., Fatigue small crack growth in a single crystal Ni-base superalloy at elevated temperature, Journal of the Society of Materials Science Japan, Vol.41, No.467 (1992), pp.1261-1267.

Reed, R. C., (2006) The Superalloys, Cambridge University Press, Cambridge.

Rengaraj, B., Baba, S., and Okazaki, M., Influence of crystal orientation on cyclic sliding friction and fretting fatigue behavior of single crystal Ni-base superalloys, In: Superalloys 2016, Hoboken, NJ, USA: John Wiley and Sons, Inc., (2016), pp. 395-404.

Shah, D. M. and Duhl, D. N., The effect of orientation, temperature and gamma prime size on the yield strength of a single crystal nickel-base superalloy, In Superalloys 1984 (1984), TMS, pp.105-114.

Suresh, S., (1998) Fatigue of Materials. Cambridge University Press, Cambridge.

Waterhouse, R. B., (1981a) Fretting fatigue. Applied Science Publishers.

Waterhouse, R. B., Fretting at high temperatures, Tribology International, Vol.14, No.4, (1981b), pp.203-207.

Zhang, X., Stoddart, P. R., Comins, J. D., and Every, A. G., High-temperature elastic properties of a nickel-based superalloy studied by surface Brillouin scattering, Journal of Physics: Condensed Matter, Vol.13, No.10 (2001), pp.22812294. 